\title{
Where Did He Go?
}

\author{
James D. Lock ${ }^{1}$
}

Received: 11 September 2017 / Accepted: 20 September 2017 /Published online: 10 October 2017

(C) Academic Psychiatry 2017

\section{Artist's Statement}

This poem is a reflection on the following questions: How are the seeds of doctoring sown? What is it about a person that prepares them for becoming a physician? How is cool and detached curiosity about the workings of the body and mind balanced with the need to be sensitive to and respectful of the delicate particulars of each person who is suffering? How is a balance of these competing interests managed during the crucible of medical training? How do we hold onto to both rigor and compassion in the face of the interfering forces of business and technology in doctoring?

\section{Where Did He Go?}

Where did he go,

that boy gathering flowers (not flowers really, but clover blossoms and dandelions, wild violets) making bouquets and woven stemmed bracelets, the walker in the morning damp awake but still dreaming uncommitted to the logos of the day?

Yet even then there was another side: tearing the tails off lightening bugs. using oozing hemolymph to stick them to his shadowed face, illuminating gory childhood grins and chin;

or, netting emerald and ruby throated humming birds, arresting their furious beating wings curious just how they worked: the makings of a healer after all.

There was the gutted body in the vat, but perhaps the cardinal colors of Clemente's atlas

James D. Lock

jimlock@stanford.edu

1 Stanford University School of Medicine, Stanford, CA, USA perched beside the cutting tray, kept something of the other aesthetic lingering in his practiced mind; or else, the captured eloquence of electron microscopic hedges bounding vesicle walls and mitochondrial fins; or, the tender pastel colored bacteria and their kin swerving unevenly, lit by the underbelly of van leeuwanhoek's device?

Or, in late night, early morning rituals,

blood drawn from punctured purple veins and squirming arteries spurting into multicolored topped vacuum tubes to assay the relative misery of a failing renal clock?

Poetry books hidden behind the clipboard, in the white jacket pocket, under the on call pillow: imposter on the ship, agent provocateur, listening to the chaos abiding in the sanctum, glistening green gems riding beneath hollowed eyes, dying things dipping wings showing the other way.

Ars medicus, the law of averages, the mean, the normal all things measured and laid down:

skinned.

Case histories, not fiction, binders, files, folders, electronic records compilations in uneven prose, structured narratives predictable conclusions, even the final drama, no deux ex machina here.

Still, at evening

Sometimes (light fading. birds singing, some notes held in trees high up echoing) he finally remembers. 